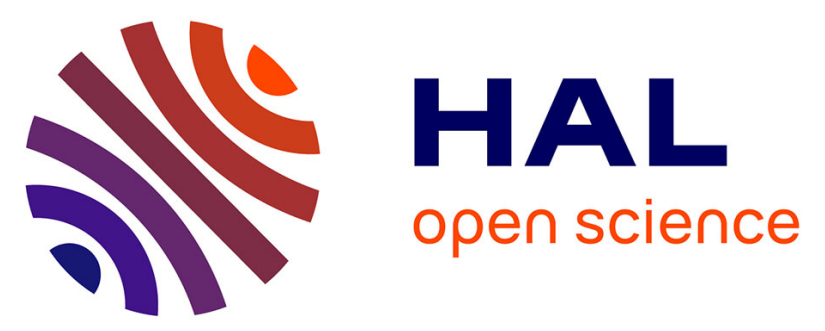

\title{
Uncertainty in the regulation systems of temporary organizations: A challenge for improving the organizational reliability
}

Florie Mazzorana-Kremer, Christophe Martin, Jean-Luc Wybo

\section{- To cite this version:}

Florie Mazzorana-Kremer, Christophe Martin, Jean-Luc Wybo. Uncertainty in the regulation systems of temporary organizations: A challenge for improving the organizational reliability. 24th European Safety and Reliability Conference - ESREL 2014, Sep 2014, Wroclaw, Poland. pp.521-530 - ISBN 9781138026810. hal-01063691

HAL Id: hal-01063691

https://hal-mines-paristech.archives-ouvertes.fr/hal-01063691

Submitted on 24 Nov 2014

HAL is a multi-disciplinary open access archive for the deposit and dissemination of scientific research documents, whether they are published or not. The documents may come from teaching and research institutions in France or abroad, or from public or private research centers.
L'archive ouverte pluridisciplinaire HAL, est destinée au dépôt et à la diffusion de documents scientifiques de niveau recherche, publiés ou non, émanant des établissements d'enseignement et de recherche français ou étrangers, des laboratoires publics ou privés. 


\title{
Uncertainty in the regulation systems of temporary organizations: a challenge for improving organizational reliability
}

\author{
F. Mazzorana-Kremer \& C. Martin \& J. L. Wybo \\ Mines Paristech / CRC, Sophia-Antipolis - France
}

\begin{abstract}
Mainstream economic and sociological theories tend to analyse organizations as permanent entities. However, industry provides many examples of organizations that are not permanent: construction projects, maintenance tasks, crisis management units, the decommissioning of nuclear plants, etc. In addition, classical theories that argue organizations should be long-lasting are inherited from the industrial revolution. Today, many organizations are becoming less rigid and are moving towards more flexible structures oriented to the short-term.

Temporary organizations differ from permanent organizations in that they are designed to have a short lifespan. They are generally created with a specific goal in mind and dissolved once this goal is reached. Different market players interact in these structures: they include distinct legal entities, freelancers or consultants who coordinate their work on a single site or from different geographic areas. Typically the temporary organization is linked to a permanent organization. In other cases, it is fully independent and those involved do not expect to work together once their objectives have been achieved. The unsustainable dimension of these organizations raises many issues in terms of risk and uncertainty.

This paper provides a better understanding of temporary organizations, their coordination, their regulatory systems and their links with the permanent parent organization (if there is one). The research described in this paper is based on a literature review. It provides a typology of temporary organizations and analyses their coordination, regulatory systems and reliability issues.
\end{abstract}

\section{INTRODUCTION}

The literature shows that a new trend has emerged in recent years: the increasingly widespread phenomenon of using temporary projects or organizations to perform some tasks or implement new services (Turner and Keegan, 2001; Lundin et al., 2003; Roy and Audet, 2002; Lundin and Söderholm, 1994; Whitley, 2006; Turner and Müller, 2003). This led to an increasing number of new, so-called temporary forms of organization. At the same time, most organizations have been subject to permanent and constant change (Bahrami, 1992; Lundin et al., 2003) which increased their reliance on ad-hoc temporary structures.

There are various kinds of temporary organizations in the industry (e.g. construction sites, periodic maintenance projects and crisis management units). They are defined by their ephemeral nature and modes of cooperation between actors which are different from the usual relationships found in traditional organizations. Often embedded into permanent organizations (particularly for large construction projects and periodic maintenance in complex socio-technical systems), these organizations show a high degree of autonomy and are sub- ject to forms of internal and external regulation that are currently poorly understood.

With respect to safety culture, the autonomy and regulation modes found in temporary organizations can lead to divergence from the objectives of the parent organization.

Risk prevention research has so far shown little interest in the parent/temporary organization relationship (Bourrier, 1999) and in the impact of these relationships on organizational reliability. The purpose of this article is to present a typology of temporary organizations, based on a literature review, and to characterize the relationships between their organizational characteristics and the reliability of sociotechnical systems.

In the first part of this article we define the temporary organization. In the second part we present the principal characteristics of this type of organization. Finally, we present an initial attempt to link these characteristics and organizational reliability.

\section{UNDERSTANDING TEMPORARY ORGANIZATIONS}

This section begins with a sample of definitions of temporary and project-based organizations. Then we propose a definition of the temporary organization 
and summarize its main characteristics with respect to permanent structures.

\subsection{Definition}

Before discussing safety concerns and organizational characteristics, it is essential to first define what a temporary organization is.

Temporary organizations are, as the wording suggests, organizations that have the particular characteristic of being "temporary". Organizations are more commonly seen as social entities that have a collective goal; they often are characterized by actors, tasks, formal and informal governance rules, regulations and their environment. In this context, temporary organizations can be seen as collective structures, focused on a specific goal - like any other organization - but with a "temporary" dimension. This temporary dimension can be related to its ephemeral nature or because their duration appears to be much shorter than the average lifetime of traditional organizations. Their temporary nature means that they are set up to meet a specific goal and are dissolved once this goal is achieved.

Compared to research on traditional organizations, there is little current literature on temporary organizations. However, a certain degree of consensus exists on the characteristics of projects, which can be seen as a particular form of temporary organization. Therefore, in order to refine and improve our definition of the temporary organization, our review included articles related to projects.

Some definitions of temporary organizations and projects are presented in the table 1 below.

Table 1. Definitions

\begin{tabular}{ll}
\hline Reference & $\begin{array}{l}\text { Definition of project / temporary organi- } \\
\text { zation }\end{array}$ \\
\hline $\begin{array}{l}\text { Goodman and } \\
\text { Goodman }\end{array}$ & $\begin{array}{l}\text { Temporary organizations involve "a set of } \\
\text { diversely skilled people working together } \\
\text { on a complex task over a limited period of } \\
\text { time." }\end{array}$ \\
\hline Keith (1978) & $\begin{array}{l}\text { "temporary systems are structures of lim- } \\
\text { ited duration that operate within and be- } \\
\text { tween permanent organizations." }\end{array}$ \\
\hline $\begin{array}{l}\text { A project is "a combination of human and } \\
\text { Kerzner (1985) }\end{array}$ & $\begin{array}{l}\text { non-human resources pulled together into } \\
\text { a temporary organization to achieve a } \\
\text { specified purpose." }\end{array}$
\end{tabular}

Turner (1990) A project is "an endeavor in which human, material and financial resources are organized in a novel way, to undertake a unique scope of work, of given specification, within constraints of cost and time, so as to achieve beneficial change defined by quantitative and qualitative objectives."

$\begin{array}{ll}\text { Lundin and } & \text { "temporary organizations are almost al- } \\ \text { Söderholm } & \text { ways motivated by a need to perform spe- } \\ \text { (1994) } & \text { cific actions in order to achieve immediate } \\ & \text { goals." }\end{array}$

Packendorff

(1995)

Lundin et al.

(2003) the ordinary organization."
"A project tends to pass through a series of
pharing its lifetime."

"Projects generally have two very characteristic features: they have been designed for a purpose so their existence is delimited in time from the moment of their creation, and they are focused on one primary task."

Turner and "A project is a temporary organization to Müller (2003) which resources are assigned to undertake a unique, novel and transient endeavour managing the inherent uncertainty and need for integration in order to deliver beneficial objectives of change."

Janowicz- $\quad$ Projects are "one of many tangible maniPanjaitan et al. festations of temporary organizations." (2009)

According to the authors, "despite the
great diversity of forms and activities tem-
porary organizations undertake (...) tem-
porariness is the only factor that is unique
to TOs, while others are simply conse-
quences or correlates thereof."

Most of these definitions are global and implicit. We consider the Goodman definition as one of the most explicit. In practice, most researchers have explored the characteristics of temporary organizations rather than provided simple definitions.

From these definitions, we argue that a temporary organization is a collective and social entity set up for a limited period of time, in order to achieve a specific goal, and dissolved when the goal is reached.

In the next section, we review a selection of relevant articles in order to determine the main characteristics of temporary organizations with respect to permanent structures.

\subsection{Main characteristics of project-based and temporary organizations}

Turner and Müller (2003) offer some insight into the definition of a project as a temporary organization. They argue that projects are unique, special forms of organization, found in businesses that use innovative and transient processes. They view the project as an organization with a production function, a temporary organization and as an agency created to guide change, use resources and manage uncertainty.

In 1994, Lundin and Söderholm, in their theory of temporary organizations, presented action as the main concept of temporary organizations. They argue that temporary organizations are almost always "motivated by the need to perform specific actions to achieve immediate goals". They defined the tem- 
porary organization in terms of the contrast with permanent organizations and highlighted the following characteristics:

-it has a limited lifespan, which is established at the outset;

-typically, the creation of a temporary organization is motivated by a task that must be accomplished;

-it consists of a team that is put in place for a known, limited period. The skills and expectations of team members provide the commitment and motivation that will enable the organization to function and accomplish its task;

-it enables transition, a change.

These characteristics highlight that the temporary organization, or an internal project, is defined by its temporality and a task to be accomplished.

However, if the temporary organization is completely assimilated to the project, there is a risk of overlooking the collective dimension of the organization. In practice, 'organization' usually refers to a set of individuals and resources that are coordinated in order to meet a shared goal (Simon, 1983). The organization is therefore often characterized by resources, individuals, the rules governing their relationships and their behaviour in order to maximize the chances of achieving the collective goal.

From this point of view, the concept of the temporary organization refers to the collective nature of action. Here, the approach put forward by Packendorff (2002) differs significantly from others and is a useful addition to our argument. The author reminds us that the literature usually defines the project as focused on a given task, which is unique, follows a set timetable, is time limited, complex to implement and evaluated. Packendorff argues that projects are often seen as tools. Little attention is given to the motivation of the individuals who participate in them; although in practice they suffer from the same dysfunctions as other organizations. He therefore suggests that "Projects should be researched in terms of culture, conceptions, relations to the environment, longitudinal processes, etc., rather than simply as goal-fulfilling subsystems whose raison d'être is provided by a decisive and strategically aware super-system."

According to Packendorff (2002), the project is a temporary organization. However, while a project is generally seen as a "tool" and only implies a user perspective, a temporary organization is constantly embodied by individuals who are continually learning from their experience and who expect to learn more. This suggests that research into temporary organizations should focus more on the actors, their expectations, their actions and what they learn.

This last point underlines the need to understand the collective dimension of this type of organization. We argue that the context for the temporary organi- zation is unstable and that its existence coincides with the achievement of an action. Specifically, it is defined by three fundamental characteristics that distinguish it from the permanent organization or project: its temporality, its predetermined time-sensitive objectives and the collective nature of the action.

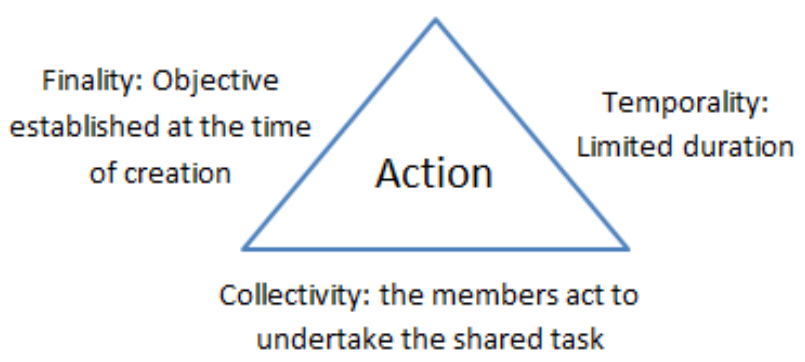

Figure 1 . The key dimensions of temporary organizations

The analysis of a temporary organization as an organization and not as a project invites us to also examine its actors, their expectations, and the problems of leadership, control and coordination.

In the next section we focus on the relationship that a temporary organization has with a permanent organization that is responsible for its creation.

\subsection{The relationship between temporary organizations and the permanent parent organization}

It is reasonable to ask what motivates the creation of a temporary organization. Some researchers, such as Modig (2007), highlight the stronger or weaker relationships that may exist between a temporary organization and the permanent organization responsible for its creation. Others (Turner and Keegan, 2001; Turner and Müller, 2003) analyse the temporary organization in terms of a project and see it as a way for a permanent organization to assume a production function while managing the uncertainty of change. It can also be the genesis of an organization (Lundin and Söderholm, 1994); for example the result of an entrepreneurial effort.

In the case where a permanent organization is responsible for creating a temporary organization, the latter generally pursues objectives that are in the interests of, and in line with those of the parent company.

In the case where a temporary organization fully independant is created, typically in response to an identified need, one or more individuals form its nucleus. In this case, the time-limited nature of the organization is more dependent on the positive motivation of its instigators. This is particularly the case with start-ups and organizations that are designed to make a short-term capital gain or profit.

We note that if a temporary organization is linked to a permanent parent organization, its collective objectives are likely to be linked to the interests of the parent organization. If this is not the case, collective 
objectives will have been set by one or more individuals before the temporary organisation was created and will correspond to their expectations or interests (financial added value, sporting or artistic events, humanitarian commitments, etc.).

In the next section we analyse its modes of operation as an organization.

\section{THE CHARACTERISTICS OF THE TEMPORARY ORGANIZATION}

As the temporary organization is a form of organization, it is interesting to analyse how it implements collective action and what issues arise related to decision-making, control, coordination and conflicts.

In this section, we look at how the temporary organization operates (particularly collectively) and we aim at highlighting the characteristics that make it different from the permanent organization, in order to understand the risks and uncertainties specific to this type of structure.

The temporary organization is, as an organization, in part defined by its objectives and the tasks to be accomplished to meet these objectives, which are assigned to people at different levels of the hierarchy (Simon, 1983). Many conditions are necessary to achieve these collective goals. Here we look in more detail at the following:

- The bond of individuals with the organization.

The activities of a group of people are only organized to the extent that they allow their bond with the organization to control their decisions and behaviour (Simon, 1983, p.99): this bond is possible only when "directly or indirectly their activity within it contributes to achieving their own goals."

- The definition and coordination of tasks, which makes it possible to centralise decisions, define the roles of members of the organization and achieve the collective goal.

- The exercise and respect for authority, which ensures the necessary coordination between actors and tasks.

- Communication, which enables the transmission and processing of the information necessary for decision-making and for the execution of tasks within the organization.

In the following sections, we analyse to what extent these conditions are met in a temporary organization.

\subsection{Individual bonds with the organization}

For an organization to function according to its initial objectives, these objectives must be compatible with those of the individuals and the objectives of the individuals must also be compatible with the organization's limited timeframe.

In practice, when members of a temporary organization are linked to or employed by its parent organization(s), they are likely to support the project if it improves their remuneration or promotion prospects. A permanent organization that prospers and grows rapidly can offer greater prestige and promotion opportunities (Simon, 1983, p.105). This means that an individual seconded by the permanent organization is likely to value the positive impact it may have on its career, once the collective goal has been met.

However, in cases where individuals working in the temporary organization are not seconded by a permanent structure, their commitment to the goals of the organization will probably depend on the potential beneficial effect on their future career, once the structure has been dissolved. In this case, their motivation may be shaped by substantial financial benefits related to the achievement of collective goals or the hope of better employability in future structures. This is only possible if their work has had high visibility vis-à-vis external actors. This idea has been put forward by Modig (2007) and Packendorff (2002) in particular, who argue that the duration of the involvement of actors and their relationship with a permanent parent organization, if any, will influence their behaviour. People who are hired for a limited time by a temporary structure will be more loyal to their network or other potential professional partners than members of the organization. This is explained by the fact that they seek to secure future employment or contracts. "There is a risk that employees whose future work opportunities or position in an organization are dependent on their visibility in earlier projects $[\ldots]$, will act opportunistically" (Modig, 2007, p. 810).

In this section we have shown that the bond that individuals form with a temporary organization is not the same as that found in a permanent organization. We also have seen that the members of the organization have a different motivation when they are employed by a permanent parent structure than when they are completely independent; the latter case can present a risk of opportunism and departure from collective goals.

We now examine issues related to the definition and coordination of tasks in temporary organizations.

\subsection{The definition and coordination of tasks}

According to Simon (1983, p. 124), the purpose of coordination is that all members of the group adopt the same decision or, more specifically, take consistent decisions, which when combined, achieve the intended goal. According to the same author, there are two types of organizational coordination: "form", which defines the domain of competence 
and the limits of the authority of each worker and "substance", which specifies the nature of the task for the individual (e.g. drawing up strategy).

According to some authors (Modig, 2007; Oerlemans et al., 2009), the definition of rules and tasks in a temporary organization depends on the role and involvement of the parent company(s) that it is linked to. In particular, research carried out by Modig (2007), although conducted on a small sample, suggests that, "the more involved a stationary 'parent' organization is in a project, the more guidelines are given as to how the temporary organization is to perform its task." However, according to the author, "Temporary organizations that are 'pure' or virtually 'pure' instead have to develop routines and procedures internally."

Modig adds that, "If work roles, relations and required skills and competencies are well defined, this can reduce the risk for rivalry and conflicts in temporary organizations and facilitate the training of new employees." It also allows the transfer of accumulated knowledge from one project to another, with the advantage of making organizations more competitive and mistakes more easily avoidable. The counterpart is that when rules are predefined, then an element of flexibility and creativity in the organization is lost. In this case, "members of temporary organizations might be more restrained than helped in their work by predefined work processes, as these can hinder them from using their knowledge and skills to develop work routines that match the unique project conditions." Modig (2007).

Oerlemans et al. (2009, p. 36) looked at collaborative temporary organizations in several German small- and medium-sized enterprises (SMEs). Based on a survey of 1,500 SMEs having participated in collaborative programs, the analysis focused on the management style chosen by the organization and founded, on the basis of four case studies, that they were managed in different ways:

Table 2. Characteristics of temporary organizations highlighted by Oerlermans et al. (2009)

No further collaboration once the project has ended

\begin{tabular}{|c|c|c|}
\hline $\begin{array}{l}\text { Collaborative } \\
\text { project under } \\
36 \text { months (av- } \\
\text { erage) }\end{array}$ & $\begin{array}{l}\text { Case 1: film produc- } \\
\text { tion } \\
\text { Coordination is pro- } \\
\text { vided by a specific } \\
\text { role such as a "direc- } \\
\text { tor" or "general con- } \\
\text { tractor". } \\
\text { Hierarchical roles } \\
\text { Work takes places in } \\
\text { a specific timeframe } \\
\text { with contractual } \\
\text { deadlines that are } \\
\text { fixed according to } \\
\text { the phases of the } \\
\text { project } \\
\text { Personal relation- } \\
\text { ships are only im- } \\
\text { portant for a few key } \\
\text { players }\end{array}$ & $\begin{array}{l}\text { Case 3: network al- } \\
\text { liances } \\
\text { Coordination is } \\
\text { provided by the lead } \\
\text { company that pro- } \\
\text { vides products and } \\
\text { services } \\
\text { Deadlines and roles } \\
\text { contractually de- } \\
\text { fined } \\
\text { Work takes place } \\
\text { according to the } \\
\text { phases of the project } \\
\text { Relationships be- } \\
\text { tween partners con- } \\
\text { tinue from one pro- } \\
\text { ject to another }\end{array}$ \\
\hline $\begin{array}{l}\text { Collaborative } \\
\text { project over } \\
36 \text { months (av- } \\
\text { erage) }\end{array}$ & $\begin{array}{l}\text { Case 2: crisis man- } \\
\text { agement } \\
\text { Coordination is pro- } \\
\text { vided by a third } \\
\text { party } \\
\text { Hierarchical roles } \\
\text { Working patterns are } \\
\text { learned and respond } \\
\text { to the needs of the } \\
\text { crisis } \\
\text { Little priority is } \\
\text { given to personal re- } \\
\text { lationships }\end{array}$ & $\begin{array}{l}\text { Case 4: major con- } \\
\text { struction project } \\
\text { Coordination is } \\
\text { handled by the lead } \\
\text { company or the } \\
\text { government agency } \\
\text { Work takes place } \\
\text { according to the } \\
\text { phases of the project }\end{array}$ \\
\hline
\end{tabular}

Other work (Janowicz-Panjaitan et al, 2007) focuses on the literature concerning project coordination or temporary organizations. The authors argue that temporary organizations are generally less formal and normative than permanent organizations. In addition, they have fewer hierarchical processes and bureaucracy and make greater use of interpersonal coordination. However, one example of interpersonal coordination is trust, and it can be difficult to build trust in a context where time is limited. To explain this, the authors refer to the work of Ness and Haugland (2005), which shows that even in a shortterm collaboration, relational norms and trust develop. According to the authors, "while hierarchical control mechanisms can supply the necessary confidence level, the trust that is necessary to assure sufficient information sharing for problem solving does evolve despite the temporary nature of a project".

The examples cited above lead us to the following conclusions: 
The definition of the roles and tasks in a temporary organization is often carried out upstream by the permanent parent organization(s) if there is one, and when there are strong links with it (Modig, 2007). However, if this is not the case, it is carried internally, by the temporary organization itself;

When a collaboration implemented by the temporary organization must be renewed after its dissolution, the lead parent company usually coordinates tasks and actors (Oerlemans et al., 2009). On the other hand, in cases where it is unlikely that the collaboration will be renewed, coordination is undertaken by a dedicated person or group belonging to the temporary organization.

Finally, temporary organizations generally have fewer formal coordination and bureaucratic processes and rely more on the interpersonal skills of their members. These informal processes require a minimum level of trust to ensure collaboration and the resolution of problems.

In the next section, we analyse the different management styles that are implemented, which make it possible for this type of organization to successfully meet its objectives.

\subsection{The managerial dimension of the temporary organization}

In an organization, management and authority are necessary to ensure respect and the coordination of tasks. Authority, according to Simon (1983, p. 119) is the relationship that coordinates the behaviour of a group by subordinating the decisions of an individual to those that are communicated by others. Individuals particularly respect authority under the following conditions: when the person who gives the orders (typically the project manager or the director of the temporary organization) is recognized as competent by peers and subordinates; when the individuals who receive the orders are responsible and naturally accept authority; when the person giving the orders has the power to sanction; when authority does not come from several persons giving contradictory orders; when the given tasks are consistent with the personal goals of the individual.

These criteria raise the question of the coexistence of several management teams. If the temporary organization does not have its own management structure, including a command unit, there is a risk of conflicts or problems with authority.

Research by Oerlemans et al. (2009) highlighted three management configurations in temporary collaborative organizations in German SMEs: comanagement by several parent organizations, management by one of the parent organizations, or management by a dedicated, project-specific team. In general, each of the three cases occurs equally often. The exception is collaborative projects with few parent organizations, in which case co-management by parent organizations is found more often.

According to Turner and Keegan (2001), uncertainty about the product and process is greater in the project context than in a classical organization or business. Simple routine management by the permanent parent organization, when there is one, may not be sufficient for the project; it may prove unsuitable and raise the risk of error, opportunism and lack of customer satisfaction.

Turner and Keegan highlight that such projects need a governance interface between them and routine operations, beyond the normal hierarchy. They argue that, in addition to the project manager who manages the project's processes, the governance structure is based on two key roles: the broker and the steward. The role of the broker is to maintain and monitor the relationship(s) with the client(s): they ensure that deliverables and products meet the expectations and needs of customers. The steward "puts together the network of resources to deliver the project, ensuring that the right people are in the right place at the right time to ensure it happens."

For the authors, depending on the type of project organization (if they manage one or multiple projects, or one or many clients), the roles of the broker and the steward will be more or less important and may be partially assumed, or not, by the project manager. In all cases, the authors note that these roles should be separate and this is what is seen in practice. There is a psychological explanation, "the broker must align with the culture of the client, whereas the steward must align with the culture of the competence pools." "The broker is essentially an extrovert, entrepreneurial role, whereas the steward is essentially an introvert, intrapreneurial ${ }^{1}$ role."

The examples cited above lead us to the following conclusions concerning the management and governance of temporary organizations or projects:

- There are three types of management in temporary organizations: co-management by many permanent parent organizations, management by one of the parent organizations, or management by a dedicated, project-specific team. (Oerlemans et al., 2009). When there are parent organizations, there is no real trend; the exception is where there are few of them, in which case it is more often that case that management is exercised by the parent organization(s).

- Whatever type of management is in place, authority must not emanate from several hierarchical superiors who manage the same tasks and may give contradictory orders.

${ }^{1}$ a person who while remaining within a larger organization uses entrepreneurial skills to develop a new product or line of business as a subsidiary of the organization. 
- When there is a permanent parent organization there should be an interface between the governance of the parent organization and that of the temporary organization (Turner and Keegan, 2001). Three key roles make this possible:

- The project manager, who manages all of the project's processes.

- The broker, who checks that the services or products meet the client's expectations and constraints.

- The steward, who organizes and mobilizes the human and technical resources necessary to obtain the services and products defined or redefined by the broker.

The latter two roles make it possible to manage on the one hand the bilateral dependency between the client (which may be the parent organization) and the project team and, on the other hand, uncertainty surrounding the product or service undertaken.

The question of authority and management is therefore important in a temporary organization as, very often, several independent individuals or structures coexist. When different control structures are shared, it is essential that they ensure the efficient coordination of tasks within the timeframe and budget constraints initially set. The next section is dedicated to another key parameter for the proper functioning of the organization: communication.

\subsection{Communication in the temporary organization}

Communication is another key element in the organization as it enables it to carry out its objectives collectively. In particular, it enables the transmission and processing of information necessary for decision-making and the execution of tasks within the organization.

According to Simon (1983), there are two types of communication in an organization: formal and informal. The formal communication system is implemented notably by discussions, letters, circulars, reports and should, according to the author, be sufficiently well organized and robust to ensure that actors and their personal interests cannot weaken the organization. The informal communication system "is built around the social relations of the organization's employees." This latter type of relationship is created spontaneously by individuals to advance their personal goals or collectively to establish their power within the organization, "it could be said that the weakness of the formal system of communication and the ensuing lack of coordination appears to encourage the formation of cliques" (Simon, 1983, p. 143). Here, cliques mean a group of individuals united by a common interest that differs or even goes against the collective interest of the organization.

Therefore, the question that arises in a temporary organization concerns the robustness of the formal communication system, which is necessary to avoid the formation of cliques that may divert the organization from its objectives. However, the limited duration of such an organization is likely to make it difficult to set up a formal communication system if it is not inherited from a permanent parent organization.

Some of the research mentioned above sheds light on the functioning of communication and the exchange of information in temporary organizations. According to Modig (2007), "All organizations need a variety of resources to perform their activities. Thus, easy access to key resources such as skilled professionals, vehicles, tools and suppliers facilitates project work considerably." The author also points out that in a temporary organization there is insufficient time and above all, a shared history to be able to implement channels for the dissemination of knowledge and information. Generally, a permanent parent organization that has a strong influence on the temporary organization will ensure that its actors have access to the resources and information necessary to meet their objectives.

For Turner and Keegan (2001), communication issues are closely related to issues of governance, which defines and provides the means to achieve a project's objectives (Müller, 2009; Turner, 2009). Communication is thus one of the problems of governance. Turner and Keegan (2001) argue that communication within a project structure is made possible and efficient through the roles of the broker and steward defined above. In order to analyse the internal and external communication needs of projects, the authors define four types of projectoriented organization: multiple small projects with a few large clients; multiple projects with multiple clients; major projects with a few large clients; and finally the start-up (comparable, according to the authors to a project associated with multiple clients).

The authors conclude that in the case of organizations managing multiple small projects with a few large clients, the role of the broker is extremely significant. In this scenario project teams are often relatively independent and it is important that communication is maintained at the interface between them and clients to ensure that the product and the service develop according to the needs of the client. In the case of a multiple projects with multiple clients, the role of the broker is as important as in the previous case but must be complemented by a strong steward who works with the broker to ensure that project teams receive the right resources in order to deliver the expected service or product. In the case of major projects with a few large clients, they note that the project manager has a direct relationship with the client and plays the role of broker. However, in the start-up case they suggest the opposite: the director (who is usually the originator of their product) plays the role of steward and ensures both internal com- 
munication and communication with suppliers in order to carry out tasks and deploy resources, while they rely on a broker for external communication.

This research suggests that communication is a key element in the temporary organization due to uncertainty about its services or products; the behaviour of actors makes it increasingly necessary to put in place functions that ensure communication between the permanent parent organization, the client (or the recipient of the goods or services), and the organization's actors.

There is less risk of cliques being created in organizations if actors' roles are defined and there is (for example through the permanent parent organization) a formal structure to ensure communication at the interface between external actors (the client) and organizational resources (suppliers and employees).

\subsection{Conclusions concerning the characteristics of temporary organizations and their regulatory systems}

Our review of the literature shows that various authors (Whitley, 2006, p.79; Lundin and Söderholm, 1994; Turner and Cochrane, 1993; Oerlemans et al., 2009, p.36; Turner and Keegan, 2001; Modig, 2007) have drawn up typologies of temporary organizations, showing that they can be distinguished from each other based on their proximity to the parent organization, the repetitive nature of their objectives, their intra or inter-organizational nature, or the tasks performed (a project to be developed, a new product or market, etc.).

A temporary organization thus appears to be a complex system composed of individuals that are independent or dependent of permanent structures and who interact with each other (whether they are employees of the same company or not), external actors, their network, clients and other businesses.

In these organizations, coordination and communication will naturally orient the behaviour of actors. However, we have seen that these measures, because of the temporary nature of the organization, are often informal and different to the relationships usually found in permanent organizations.

Returning to the work of Turner and Keegan (2001), temporary organizations operate through the action of a few key players: the project manager, the broker and steward, who are responsible for integration and coordination. Other studies (Modig 2007; Oerlemans et al., 2009; Turner et Cochrane, 1993) show that coordination, authority and communication, which contribute to the regulation of these atypical systems, are also conditioned by external systems such as the permanent parent organization, which is linked to the temporary organization.

Therefore, there is a great uncertainty with respect to the ways in which the actors and subsys- tems of these organizations regulate themselves in order to reconcile interests, individual behaviours and collective goals.

\section{TEMPORARY ORGANIZATIONS AND RELIABILITY ISSUES}

In this section, we examine two types of risk: risks created when the temporary organization is conceived and risks associated with the temporary nature of this type of organization.

\subsection{Risks insufficiently taken into account in the design phase}

The analysis of the characteristics of temporary organizations has shown that tasks can be organized upstream, by the permanent organization or the temporary organization itself (if it is semi-independent). However, most of the time, as is the case for temporary organizations established for infrastructure projects (power plants, construction sites) or decommissioning (end-of-life oil fields, nuclear power plant decommissioning or waste treatment installations, etc.), operating budgets are often set in advance. This predetermined factor makes it difficult to assess the technical and financial risks once the temporary organization has been established and its tasks have been defined. Safety issues often appear after the design of a project has been fixed and its budgets determined by the various companies involved (Koppenjan, 2001), "Since finding a balance between various interests is a delicate matter, such a disturbance may even jeopardize the realization of the project." This issue raises two fundamental problems: first, when the temporary organization is initiated, there is a need to define and anticipate risk upstream so that the project's budget and its capacity are correctly assessed; second, the interests of key individuals in the organization must not be an obstacle to the communication of any difficulties encountered as the project progresses - even if this jeopardises the entire project and raises questions about the personal interests of individual stakeholders.

Similarly, the flexibility of temporary organizations, which is based on good interpersonal communication (that is more informal than formal) raises ethical issues. In particular, how is it possible to ensure that project managers and other key individuals will communicate with each other and disclose safety issues that appear once the structure is in place, if their personal interest is limited to their role in the temporary structure and the achievement of objectives? We argue that there is currently insufficient research into the methods and formal systems (both in terms of communication and governance), which should be implemented upstream in temporary organizations to ensure that technical and human risks and divergences from objectives are given 
sufficient weight. Serious care should be taken to the control modes of actors, which take into account the risks incurred during and after the lifespan of the temporary organization.

\subsection{Risks related to the temporary nature of the organization}

As we have shown, definitions of temporary organizations highlight their limited duration, task orientation and uncertainty. We argue that these criteria lead to specific risks.

First, one of the most important features of temporary organizations is their limited duration. This short lifetime, according Janowicz-Panjaitan et al. (2009) leads to several problems including: lack of time to develop a relevant shared knowledge base, to plan organisational change and to develop trusting long-term interpersonal relations. Furthermore, the author refers to the work of Weick $(1993$, p. 644) to highlight the fact that the organization, when viewed in the short term, prevents its members from developing goals that transcend their personal interests.

On the other hand, Janowicz-Panjaitan et al. (2009) suggest that when time limitations and the date or the conditions for the dissolution of the organization are known by its members from the beginning, they will feel under greater time pressure than in classical organizations. The work may become more pressurised and is therefore more likely to lead to deviations or errors than in conventional organizations.

Similarly, the uncertainty inherent to temporary organizations may pose more problems than in permanent organizations. Team members have less shared task knowledge; collective learning is lacking and the uncertainties faced by members of the organization must be managed, starting from their ability to communicate and identify problems.

The task-oriented character of temporary organisations makes their members more focused on getting the work done, which can lead to improved performance. On the other hand, they will be less influenced by other factors; the environment and potential risks are not likely to be priorities, due notably to the "emergency" requirement to achieve objectives.

Finally, the time-limited and task-oriented nature of the temporary organization raises issues of psychosocial risk and organizational reliability. Individuals in these organizations are likely to be under more pressure; in addition they are less likely to be loyal to an organization that is doomed to be quickly dissolved than a permanent organization.

\section{DISCUSSION}

Based on a literature review, our research consisted in describing temporary organizations that we first defined as "collective and social entities set up for a limited period of time, in order to achieve a specific goal". It appears to us that key features of such organizations are their temporariness, their set-inadvance objectives as well as their collective nature. They also are often linked to permanent parent structures and such link can naturally impact the nature of their tasks and goals.

We have highlighted some of the characteristics of temporary organizations: they generally have fewer formal coordination and bureaucratic processes; they rely more on the interpersonal skills of their members; they need specific roles - between their working staff and their external environment - in order to ensure an efficient communication and a proper completion of their tasks.

Thus, our analysis leads us to see them as atypical and complex structures. Such complexity, associated with a high level of autonomy, seem to raise many issues in terms of risk and reliability. First of all, it is obvious that the limited duration of temporary organizations can represent a stressful environment for individuals. It also let little time for the creation of a common knowledge necessary for the successful completion of the collective tasks and goals. Secondly, because the tasks, objectives and financial budgets of such organizations are often determined in advance, an afterwards emerging risk might endanger their survival much more than in a permanent organization. For these reasons, when they are linked to a permanent parent company, project managers, or some other key players, may be reluctant to communicate problems if these ones endanger the survival of the temporary organization they are involved in.

Therefore, the issue of the reliability of temporary organizations with respect to the parent organization needs more research founded in organizational theory and oriented towards the energy sector where this type of organizations is widespread and the safety stakes are high.

\section{REFERENCES}

Bahrami, H., 1992, The Emerging flexible organization: perspectives from Silicon Valley. California Management Review, Summer 1992, 33-52.

Bourrier, M., 1999, Le nucléaire à l'épreuve de l'organisation. Le travail humain, Paris, Presses universitaires de France, $294 p$.

Cleland, D.I. and Kerzner, H.A., 1985, Project management dictionary of terms. New York: Van Nostrand Reinhold.

Goodman, R.A. and Goodman, L.P., 1976, Some management issues in temporary systems: a study of professional development and manpower - the theatre case, Administrative Science Quaterly, 21, 494-501. 
Janowicz-Panjaitan, M., Bakker, R.M. and Kenis, P., 2009, Research on temporary organizations: the state of the art and distinct approaches toward temporariness. In Kenis, P., Janowicz-Panjaitan, M., and Cambre, B. (Eds.). Temporary Organizations: Prevalence, logic and effectiveness. Northampton, MA: Edward Elgar.

Keith, P.M., 1978, Individual and organizational correlates of a temporary system, The Journal of Applied Behavorial Science, 14 (2), 195-203.

Koppenjan, J., 2001, Project development in complex environments: assessing safety in design and decision-making. Journal of contingencies and crisis management, Vol 9 (3), 121-130.

Lundin, R.A., Runólfur, S., Steinhórsson, R. and Audet, M., 2003, Studying organizations as temporary. Scandinavia Journal of Management, 19, 233-250

Lundin, R.A. and Söderholm, A., 1994, A theory of the temporary organization. Scandinavia Journal of Management, 11, 437-455.

Miles, M.B., 1964, On temporary systems', in M.B. Miles (ed.), Innovation in education. New York, NY: Teachers, College, Columbia University, pp. 437-490.

Modig, N., 2007, A continuum of organizations to carry out projects. International Journal of Project Management. 25, $807-814$

Müller, R., 2009, Project governance. Fundamentals of Project Management Series, Gower Publishing: Aldershot, UK.

Ness, H. and Haugland, S.A., 2005, The evolution of governance mechanisms and negotiation strategies in fixedduration interfirm relationships, Journal of Business Research, 58, 1226-1239.

Oerlemans, L., de Kok, J. and de Jong, J., 2009, The prevalence and characteristics of interorganizational temporary collaborations of Dutch small and medium sized firms (SMEs). In Kenis, P., Janowicz-Panjaitan, M., and Cambre, B. (Eds.). Temporary Organizations: Prevalence, logic and effectiveness. Northampton, MA: Edward Elgar.

Packendorff, J., 1995, Inquiring into the temporary organization: new directions for project management research. ScamL Journal of Management. Vol. 11 (4), 319-333.

Packendorff, J, 2002, The temporary society and its enemies. Projects from an individual perspective. In: SahlinAndersson, K. and Söderholms, A., editors. Beyond project management: New perspectives on the temporary - permanent dilemma. Malmö : Liber ekonomi, p348.

Roy, M. and Audet, M., 2002, La transformation vers de nouvelles formes d'organisation plus flexible: un cadre de référence. HEC Montreal. Gestion, Vol. 27, p. 43-49.

Simon, H.A., 1983, Administration et processus de décision. Economica, French translation.

Turner, J.R. and Cochrane, R.A., 1993, Goals-and-methods matrix: coping with projects with ill defined goals and/or methods of achieving them, International Journal of Management, 11 (2), 93-102.

Turner, J.R., 1990, What are projects and project management? Henley Working Paper 9002. Henley-on-Thames: Henley Management College.

Turner, J.R. and Keegan, A., 2001, Mechanisms of governance in project-based organization: Roles of the Broker and Steward. European Management Journal. Vol 19 (3), 254267.

Turner, J.R. and Müller, R., 2003, On the nature of the project as a temporary organization. International Journal of Project Management, 21, 1-8.

Turner, J.R., 2009, The handbook of project-based management (3rd ed.). New York, NY: McGraw-Hill.

Weick, K.E., 1993, The collapse of sensemaking in organizations: The Mann Gulch disaster, Administrative Science Quarterly, 38, 628-652.
Whitley, R., 2006, Project-based firms: New organizational form or variation on a theme? Industrial and Corporate Change, 15 (1), 77-99. 